\title{
Guest editors' tribute to Nina Fjodorovna Zakharchuk on the occasion of her 75th birthday on July 28th, 2012
}

\author{
Fritz Scholz • Elena Korotkova
}

Received: 28 March 2012 / Accepted: 28 March 2012 /Published online: 4 May 2012

(C) Springer-Verlag 2012

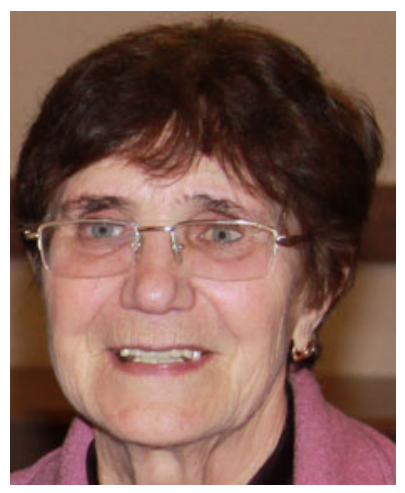

Nina Fjodorovna Zakharchuk was born in Omsk Oblast (southwestern Siberia), the daughter of a farmer in the then Soviet Union. She studied chemistry at the University of Alma-Ata (now Almaty) in Kazakhstan where she worked for her PhD (in USSR/Russia: candidate of science degree) with Ol'ga Alfredovna Songina (1901-1989), one of the leading Soviet scientists in electrochemical analysis. Since 1966 she has worked at the Nikolaev Institute of Inorganic Chemistry in Novosibirsk (Akademgorodok), in the Analytical Laboratory which was headed from 1964-1989 by the

\footnotetext{
F. Scholz ( $\square)$

Institut für Biochemie, Universität Greifswald,

Felix-Hausdorff-Straße 4,

17487 Greifswald, Germany

e-mail: fscholz@uni-greifswald.de

E. Korotkova

Tomsk Polytechnic University,

Lenin av. 30, TPU,

Tomsk 634050, Russia

e-mail: eikor@mail.ru
}

famous analytical chemist Iosif Herschevich Judelevich (1920-1993). Over her lifetime, Nina Fjodorovna has contributed significantly to a wide spectrum of topics in electrochemistry and electroanalysis, especially stripping voltammetry. One of her most important achievements has been the development of electrochemical methods of phase analysis. In particular, she has developed techniques which allow one to obtain specific signals for various phases when the latter are present on electrode surfaces. This technique has found wide application in the phase analysis of oxide films on semiconductor surfaces. In addition, she has cooperated widely with solid state chemists inside her Institute, and has succeeded in studying the electrochemistry of various metal cluster compounds and high-temperature superconducting phases.

Besides solid phase analysis, Nina Fjodorovna has also had a long-standing interest in graphite paste electrodes for electrochemical phase analysis, and several of her papers concern the preparation and properties of mercury film electrodes for stripping voltammetry of soluble species. Indeed, stripping voltammetry has always been of central concern to her, and in this field she has contributed a large number of important papers. Recently, she has even extended her research to the field of biochemical analysis, such as the determination of thiols and disulfides in blood. Her opus of papers is a treasure which has still not been fully exploited, especially outside the Russian-speaking world. Although she has published in English for two decades, a number of her major papers remain untranslated - a challenge for our Russian colleagues.

This homage to Nina Fjodorovna Zakharchuk would be incomplete without some mention of her personality: she is a most modest scientist, indifferent to honours, preferment, or power (“... thou hast not asked riches, wealth, or honour ... but hast asked wisdom and knowledge for thyself, ...; Wisdom and 
knowledge is granted unto thee..." / 2 Chronicles 1:11, 12). ${ }^{1}$ She continually strives to get deeper insights into Nature, to answer scientific questions, and to help her fellow scientists to solve their problems. She is also a highly gifted experimentalist, with a remarkable intuition for good experimental design. Her laboratory skills are further complemented by her clear thinking and clinical phrasing. One of the present authors (FS) had the good fortune to cooperate with her in the nineties, when she was a guest scientist at Humboldt University in Berlin, and he can personally attest to Nina's remarkable personality which rapidly allowed her to make many new friends among the University staff and foreign guests.

Whilst preparing this special issue, her colleagues from Russia have contributed their own tribute to Nina, from which we should like to cite some passages. "There is much that could be said about Nina Fjodorovna, but the main thing that distinguishes her from others is the lively gleam in her eyes, which shines particularly brightly in those moments when she is totally absorbed in her work.
Quite frankly, it is very rare to find anyone who is so much in love with their work. This frail woman deserves our utmost admiration for the courage and persistence with which she explores unknown worlds, and overcomes thorny obstacles, to reach her goal. Nina Fjodorovna Zakharchuk is a paragon of efficiency, creativity and passion, and she inspires students and colleagues alike with her powerful energy. Despite numerous setbacks and illnesses, she has toiled unrelentingly all her life, and maintained her presence of mind throughout, even when the problems seemed intractable. And what fruits have emerged from her garden! Humane, hospitable, sympathetic and tolerant - these are the virtues that Nina Fjodorovna Zakharchuk represents to us! (The team of Analytical Laboratory of the Institute of Inorganic Chemistry SB RAS)"

Remarkably, Nina Fjodorovna Zakharchuk is still working at her famous Institute, and the light of her intellect shines undimmed. In this special issue her many friends and colleagues from around the world wish her good health and continuing enjoyment of science for many years to come!

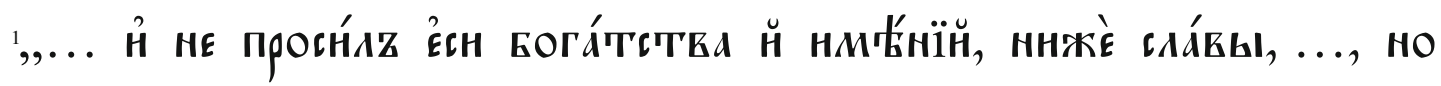

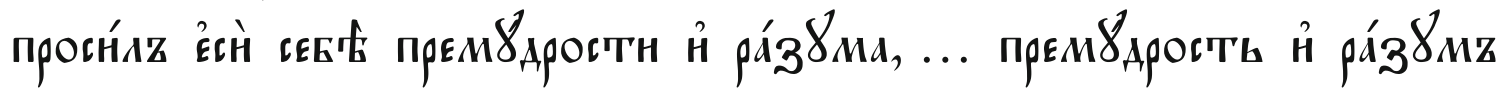
AAT' TEE'..." 